\title{
Identification and Functional Analysis of CITED2 Mutations in Patients With Congenital Heart Defects
}

\author{
Silke Sperling, ${ }^{1 *}$ Christina H. Grimm, ${ }^{1}$ Ilona Dunkel, ${ }^{1}$ Siegrun Mebus, ${ }^{2}$ Hans-Peter Sperling, ${ }^{2}$ \\ Arno Ebner, ${ }^{3}$ Raffaello Galli, ${ }^{1}$ Hans Lehrach, ${ }^{1}$ Christoph Fusch, ${ }^{3}$ Felix Berger, ${ }^{2}$ and Stefanie Hammer ${ }^{1}$ \\ ${ }^{1}$ Max Planck Institute for Molecular Genetics, Berlin, Germany; ${ }^{2}$ German Heart Center Berlin, Berlin, Germany; ${ }^{3}$ Department of Pediatrics, \\ Ernst-Moritz-Arndt University, Greifswald, Germany
}

Communicated by Mark H. Paalman

Recent reports have demonstrated that mice lacking the transcription factor Cited 2 die in utero showing various cardiac malformations. We present for the first time functionally relevant mutations of CITED2 in patients with congenital heart defects (CHDs). CITED2 encodes a CREBBP/EP300 interacting transcriptional modulator of HIF1A and TFAP2. To study the potential impact of sequence variations in CITED2 for CHDs in humans, we screened a cohort of 392 well-characterized patients and 192 control individuals using DHPLC, sequencing, and Amplifluor $^{\mathrm{TM}}$ genotyping techniques. We identified 15 CITED2 nucleotide alterations. Seven of these alterations were found only in CHD patients and were not detected in controls, including three mutations leading to alterations of the amino acid sequence (p.Ser170_Gly178del, p.Gly178_Ser179ins9, and p.Ser198_Gly199del). All three of these amino acid changing mutations cluster in the serine-glycine-rich junction of the protein, to which no functionality had heretofore been assigned. Here we show that these mutations significantly reduce the capacity of CITED2 to transrepress HIF1A, and that the p.Ser170_Gly178del mutation significantly diminishes TFAP2C coactivation. This reveals a modifying role for the serine-glycinerich region in CITED2 function. In summary, the observation of these mutations in patients with septal defects indicates that CITED2 has a causative impact in the development of CHD in humans. Hum Mutat 26(6), 575-582, 2005. (C) 2005 Wiley-Liss, Inc.

KEY WORDS: CITED2; congenital heart defects; CHD; septal defects; arterial malrotation

\section{INTRODUCTION}

Congenital heart defects (CHDs) account for the largest number of birth defects in humans, with an incidence of about eight per 1,000 live births and are the leading noninfectious cause of mortality in newborns. Although major insights into the cardiac developmental process have been gained in studies of animal models, such as mice, chicken, and zebrafish, little is known about the genetic basis in humans. The overwhelming majority of congenital heart malformations do not segregate in Mendelian ratios, although they show familial aggregation, which suggests that genetic factors play a role in their development. Almost 30\% of major cardiac malformations are associated with additional developmental abnormalities and result from a recognized chromosomal anomaly or occur as part of a syndrome. Primarily based on knowledge gained from model organisms, disease genes have been identified in a few syndromes, familial nonsyndromic conditions, and very few sporadic cases. The identified disease genes point to a key role of transcription factors in the process of cardiac maldevelopment. It has been demonstrated that TBX5 (MIM\# 601620) mutations are frequent causes of Holt-Oram syndrome (MIM\# 142900) [Basson et al., 1997; Li et al., 1997] and mutations in the transcriptional coactivators CREBBP (MIM\# 600140) and EP300 (MIM\# 602700) are associated with cardiac malformations in Rubinstein-Taybi syndrome (MIM\# 180849) [Petrij et al., 1995; Roelfsema et al., 2005]. Moreover, causative gene defects have been described for nonsyndromic congenital heart malformations, e.g., mutations in the cardiac transcription factors NKX2.5 (MIM\# 600584) and GATA4 (MIM\# 600576) [Schott et al., 1998; Garg et al., 2003; Pizzuti et al., 2003; Reamon-Buettner and Borlak, 2004; Ware et al., 2004; Ching et al., 2005]. The heterogeneity of CHDs associated with singlegene defects in patients, and the broad phenotype spectrum seen in mouse models point to a complex genetic network with modifier genes, genetic polymorphisms, and the influence of environmental factors [Bamford et al., 2000; Srivastava, 2001; Solloway and Harvey, 2003; Olson, 2004]. For example, human mutations in the cardiac homeobox protein NKX2.5 cause a diverse set of congenital heart malformations that include septal defects, cardiomyopathy, outflow tract defects, hypoplastic left heart, and associated arrhythmias. Here we present an analysis of the CITED2 (MIM\# 602937) gene in a patient cohort representing

Received 13 April 2005; accepted revised manuscript 16 August 2005.

*Correspondence to: Silke Sperling, Max Planck Institute for Molecular Genetics, Ihnestr. 73,14195 Berlin, Germany.

E-mail: sperling@molgen.mpg.de

Grant sponsor: Bioprofile; Grant numbers: BMBF; Bioprofile 0313040B; Grant sponsor: Max Planck Society (Tandem Project).

DOI 10.1002/humu.20262

Published online in Wiley InterScience (www.interscience.wiley.com). 
a broad phenotype spectrum, and show for the first time its impact as a disease gene for CHDs in humans.

CITED2 is an ubiquitously expressed hypoxia-inducible transcriptional cofactor and interacts with high affinity with CREBBP and EP300 [Bhattacharya et al., 1999; Leung et al., 1999; Freedman et al., 2003]. This binding competitively inhibits the interaction between EP300 and the transcription factor HIF1A (MIM\# 603348), blocking transcriptional activation by HIF1A. Further, CITED2 coactivates TFAP2 isoforms (MIM\#s 107580, 601601, 601602) and both can be detected together at the Pitx2c (MIM\# 601542) promoter in embryonic mouse hearts. This suggests that CITED2 plays a role in left-right patterning through the Nodal-PITX2C pathway [Braganca et al., 2003; Bamforth et al., 2004; Weninger et al., 2005]. CITED2 is essential for normal development of the heart, as evidenced by the fact that mice lacking Cited2 die in utero showing various cardiac malformations including atrial and ventricular septal defects, right-sided aortic arches, double-outlet right ventricle, common arterial trunk and overriding aorta [Bamforth et al., 2001, 2004; Weninger et al., 2005]. Deficiencies in TFAP2 coactivation have been suggested to cause laterality defects in Cited $2-/-$ mice, but also dysregulation of hypoxia-activated gene transcription may account for the cardiac malformations seen in Cited2-/- embryos [Yin et al., 2002].

In the present study we performed a mutation screen of the CITED2 gene in a cohort of patients with well-characterized phenotypes of sporadic nonsyndromic CHD [Kaynak et al., 2003]. Novel CITED2 mutations were identified and their functional significance was investigated by transactivation and subcellularlocalization assays. The results indicate that CITED2 has a causative impact on the development of CHD in humans.

\section{Patient Samples}

MATERIALS AND METHODS

Patient blood samples were obtained from the German Heart Center after ethics approval was granted by the institutional review committee and informed consent was obtained from the patients or their parents. Phenotypic information was documented in detail in a cardiovascular genetic database established at the Max-Planck-Institute for Molecular Genetics [Seelow et al., 2004]. Genomic DNA was prepared from the blood samples by standard procedures, and DNA was purified when necessary using DNA Cleanup (Qiagen, Hilden, Germany; www.qiagen.com). Control DNA samples were obtained from the Community and Molecular Medicine Newborn Survey (University Hospital Greifswald, Greifswald, Germany).

\section{Mutation Detection}

Both exons of the human CITED2 gene, including the entire $5^{\prime}$ and 3' untranslated regions (GenBank: NM_006079.3), were amplified by PCR using the primers described in Table 1A. All PCR reactions were performed using $50 \mathrm{ng}$ of genomic DNA, 200 $\mu \mathrm{M}$ of dNTPs and $500 \mathrm{nM}$ of primer. PCR products were denatured for $10 \mathrm{~min}$ at $95^{\circ} \mathrm{C}$ and subjected to denaturing HPLC (DHPLC) analysis on the automated WAVE ${ }^{\mathrm{TM}}$ nucleic acid fragment analysis system (Transgenomic, San Jose, CA; www.transgenomic.com) as described previously [Eng et al., 2001]. The fragments were eluted with temperatures calculated by the DHPLC melt program for the successful resolution of heteroduplexes (http://insertion.stanford.edu/melt.html) [Jones et al., 1999]. Samples with double- or triple-peaked DHPLC chromatograms were purified using Qiagen PCR purification and sequenced by the Services in Molecular Biology Company (Berlin, Germany).

\section{Amplifluor $^{\mathrm{TM}}$ Allele-Specific PCR}

The Amplifluor ${ }^{\mathrm{TM}}$ genotyping assay based on PCR amplification in the presence of tailed allele-specific primers, a common reverse primer, and universal fluorescence labeled Amplifluor ${ }^{\mathrm{TM}}$ primers (Serologicals, Temecula, CA; www.serologicals.com) was performed as described previously [Myakishev et al., 2001; Rickert et al., 2004]. The primers designed by the Amplifluor ${ }^{\text {TM }}$ assay architect software (www.assayarchitect.com) are listed in Table 1B. The 5- $\mu$ l amplification reactions contained $25 \mathrm{nM}$ of FAM- and JOE-labeled Amplifluor ${ }^{\mathrm{TM}}$ primers, $25 \mathrm{nM}$ of tailed allele-specific primers, $375 \mathrm{nM}$ of reverse primer, $1 \times$ reaction buffer (Serologicals), $0.2 \mathrm{mM}$ of dNTPs, $0.25 \mathrm{U}$ of HotStar Taq Polymerase (Qiagen), and $20 \mathrm{ng}$ of genomic DNA. The amplification profiles were as follows: $96^{\circ} \mathrm{C}, 10 \mathrm{~min} ;\left(95^{\circ} \mathrm{C}, 30 \mathrm{sec} ; 56^{\circ} \mathrm{C}, 30 \mathrm{sec} ; 72^{\circ} \mathrm{C}\right.$, $40 \mathrm{sec}) \times 45$ cycles; $72^{\circ} \mathrm{C}, 3 \mathrm{~min}$. The amplification signals were analyzed via endpoint measurement using the ABI Prism 7900HT system (Applied Biosystems, Darmstadt, Germany; www.applied biosystems.com).

\section{Haplotype Analysis}

Haplotype structure was determined using HAPLOVIEW [Barrett et al., 2005]. Linkage disequilibrium (LD) was calculated as $\mathrm{D}^{\prime}$ values using an expectation-maximization (EM) algorithm, and haplotype frequencies comparing the patient and the control cohort were analyzed by $\chi^{2}$ tests.

\section{Plasmids}

The open reading frames of wild-type (wt) and mutant CITED2 were amplified by PCR from genomic DNA and cloned into pcDNA3.1(+) (Invitrogen, Karlsruhe, Germany; www.invitro gen.com) to obtain expression vectors for CITED2-wt and the CITED2 mutants. The resulting clones were verified by sequencing. To create $\mathrm{N}$ - and C-terminal GFP-CITED2 fusion proteins, the open reading frames were amplified by PCR from the plasmid DNA and cloned in frame into pEGFP-N1 and pEGFP-C1 (BD Biosciences, Palo Alto, CA). The HIF1A reporter system pGal4HIF1A and pGal4-Luc was described previously and kindly provided by L.E. Huang (NCI, Bethesda, MD) [Huang et al., 1998]. The pGal4-HIF1A plasmid contains the Gal4-DNA binding domain fused to the C-terminal transactivation domain of HIF1A, which is stable under nonhypoxic conditions. In pGal4Luc the Luciferase reporter gene is under the control of Gal4DNA binding sites. The TFAP2 responsive reporter plasmid pAP2-Blue harboring a Luciferase reporter gene under the control of three TFAP2 response elements, and the human TFAP2C expression plasmid pRSV-TFAP2C were a kind gift from Helen Hurst (Hammersmith Hospital, London, UK) [Bosher et al., 1996; Bamforth et al., 2001].

\section{Transcriptional Assay}

HepG2 cells were maintained in Dulbecco's modified Eagle's medium with $10 \%$ fetal bovine serum. Cells were seeded into 96 well plates and on the next day at $60 \%$ confluency were transfected using Fugene6 (Roche, Mannheim, Germany; www.roche-applied-science.com) according to the manufacturer's instructions. Wt and mutant CITED2 constructs or empty vector were cotransfected together with pGal4-HIF1A and pGal4-Luc or pRSV-TFAP2C and pAP2-Blue, respectively. In all wells a pRL-TK Luciferase vector (Promega, Mannheim, Germany; www.prome 
TABLE 1. Primers Used for CITED2 Amplification and Allele-Specific PCR

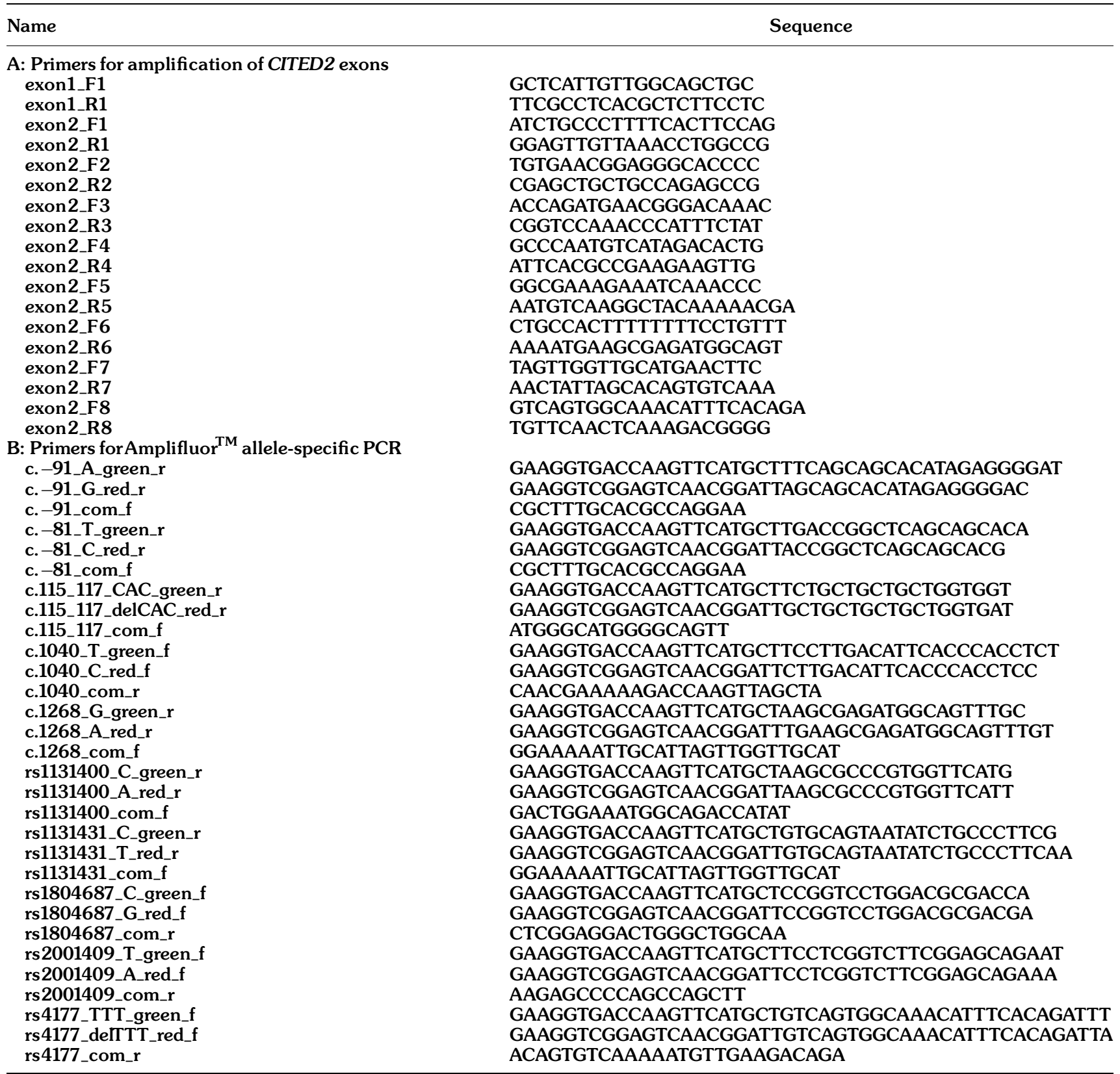

ga.com) was cotransfected to control for transfection efficiency. Subsequently, $40 \mathrm{hr}$ after transfection the cells were washed with phosphate-buffered saline (PBS) and lysed in $50 \mu \mathrm{l}$ of passive lysis buffer (Promega). Firefly and Renilla Luciferase activities were measured using the Dual-Luciferase-Reporter Assay System (Promega) in a Centro LB960 luminometer (Berthold, Bad Wildbad, Germany; www.berthold.com). Firefly Luciferase activities were normalized to Renilla Luciferase activity and the results for the samples transfected with CITED2-wt construct were set to $100 \%$. The results shown represent a minimum of three independent experiments performed in at least triplicates.

\section{Immunofluorescence and Subcellular Localization}

HepG2 and HEK293 cells were seeded onto glass coverslips $6 \mathrm{hr}$ prior to transfection at about $60 \%$ confluency. GFP-CITED2 expression constructs containing wt and mutant CITED2 were transfected using Fugene6 (Roche) according to the manufacturer's instructions. Then $48 \mathrm{hr}$ after transfection, the cells were fixed in 4\% paraformaldehyde/PBS at RT for $15 \mathrm{~min}$, washed in PBS, and mounted with Vectashield containing DAPI (Vector Laboratories, Inc., Burlingame, CA; www.vectorlabs.com). The cells were analyzed by fluorescence microscopy.

\section{RESULTS \\ Phenotypes of the Analyzed CHD Patient Cohort}

CITED2 mutation analysis was performed using DHPLC analysis in a cohort of 392 unrelated nonsyndromic patients who showed a broad spectrum of CHDs. The cardiac phenotypes of the analyzed patients are described in Table 2. To allow a more detailed visualization of the panel of analyzed CHD phenotypes in the overall patient cohort, as well as their association with the 
observed genotypes, we have set up a freely accessible interactive Web supplement using the database front-end d-matrix applied to our cardiovascular genetics database (http://dmatrix.molgen.mpg.de/SV) [Seelow et al., 2004]. A further 192 individuals from the Greifswald Newborn Survey served as controls.

\section{Identification of CITED2 Mutations}

From a total of 392 patient samples, we identified five sequence variations that were already listed in dbSNP (NCBI), as well as 10 novel CITED2 nucleotide alterations (three amino acid deletions, one amino acid insertion, one amino acid substitution, one silent nucleotide alteration, two nucleotide substitutions in the $5^{\prime} \mathrm{UTR}$, and two alterations in the $3^{\prime}$ UTR). The localization of these sequence variations and the predicted effects on the CITED2 amino acid sequence, as well as the frequencies detected in CHD patients and controls, are shown in Table 3. Seven of the novel sequence variations were detected only in CHD patients and not

TABLE 2. Congenital Heart Defects of Analyzed Patients

\begin{tabular}{lc}
\hline & $\begin{array}{c}\text { Patients } \\
\text { genotyped } \\
\text { Cardiovascular anomalies }\end{array}$ \\
\hline Situs inversus totalis & $5(1.3 \%)$ \\
Dextrocardia & $2(0.5 \%)$ \\
D-transposition of the great arteries & $21(5.4 \%)$ \\
Right aoortic arch & $30(7.7 \%)$ \\
Secundum atrial septal defect & $129(32.9 \%)$ \\
Sinus venosus atrial septal defect & $26(6.6 \%)$ \\
Partial anomalous pulmonary venous return & $11(2.8 \%)$ \\
Perimembranous ventricular septal defect & $180(45.9 \%)$ \\
Incomplete atrioventricular septal defect & $3(0.8 \%)$ \\
Complete atrioventricular septal defect & $16(4.1 \%)$ \\
Tetralogy of Fallot & $46(11.7 \%)$ \\
Hypoplastic left heart syndrome & $2(0.5 \%)$ \\
Pulmonary atresia & $14(3.6 \%)$ \\
Pulmonary stenosis & $56(14.3 \%)$ \\
Double inlet left ventricle & $1(0.3 \%)$ \\
Double outlet right ventricle & $13(3.3 \%)$ \\
Left superior vena cava & $29(7.4 \%)$ \\
Aortic isthmus stenosis & $19(4.8 \%)$ \\
\hline
\end{tabular}

in controls, namely c. $-91 \mathrm{G}>\mathrm{A}$, and c. $-81 \mathrm{~T}>\mathrm{C}$ in the untranslated 5' region; c.456C $>$ T, c.508_534del27 (p.Ser170_ Gly178del), c.534_535ins27 (p.Gly178_Ser179ins9), and c.592_ 597delAGCGGC (p.Ser198_Gly199del) in the coding region; and c.1268A $>\mathrm{G}$ in the untranslated $3^{\prime}$ region (nomenclature based on GenBank NM_006079.3, CITED2 cDNA, with +1 corresponding to A of the initiation codon; www.hgvs.org/mut nomen/). All patient-exclusive mutations that alter the amino acid sequence of CITED2 (p.Ser170_Gly178del, p.Gly178_Ser179ins9, and p.Ser198_Gly199del) cluster in the serine-glycine-rich junction [Leung et al., 1999] of the protein (Fig. 1).

The phenotype characteristics of patients with potential disease-causing mutations are shown in Table 4. We observed amino acid altering mutations in one patient with a sinus venosus atrial septal defect and abnormal pulmonary venous return to the right atria, one patient with an atrial septal defect of the secundum type (ASDII), and one patient with a perimembranous ventricular septal defect (VSD). Furthermore, we found non-amino acid altering mutations in two patients with tetralogy of Fallot; one patient with situs inversus totalis, transposition of the great arteries, and perimembranous VSD; one patient with perimembranous VSD and ASDII; and one patient with perimembranous VSD and right ventricular outflow tract stenosis.

\section{Influence of CITED2 Mutations on TFAP2 Transactivation and HIF1A Transrepression}

To assess the functional significance of the amino acid altering CITED2 mutations found in CHD patients, we tested their influence on reporter gene transactivation and repression. To date, no functionality has been assigned to the serine-glycine-rich junction of the protein harboring the observed mutations. Previous reports showed that CITED2 acts as a binding partner and transcriptional coactivator of TFAP2 [Bamforth et al., 2001], and interacts with the histone acetylases CREBBP/EP300 via its Cterminus. The latter leads to a transcriptional repression of HIF1A due to overlapping binding sites [Bhattacharya et al., 1999]. In our experiments CITED2-wt coactivated the TFAP2C-mediated stimulation of a TFAP2-reporter construct, as described previously [Bamforth et al., 2001]. However, the p.Ser170_Gly178del mutant

TABLE 3. Localization and Frequencies of CITED2 Variants

\begin{tabular}{|c|c|c|c|c|c|c|c|c|c|}
\hline \multirow[b]{2}{*}{ dbSNP } & \multirow[b]{2}{*}{ Position } & \multirow[b]{2}{*}{$\begin{array}{l}\text { Nucleotide } \\
\text { variation }^{\mathrm{a}}\end{array}$} & \multirow[b]{2}{*}{ Amino acid variation } & \multicolumn{3}{|c|}{ Patients } & \multicolumn{3}{|c|}{ Controls } \\
\hline & & & & $\begin{array}{l}\text { Mut } \\
\text { chr }\end{array}$ & $\begin{array}{c}\text { Total } \\
\text { chr }\end{array}$ & $\begin{array}{l}\text { Mut allele } \\
\text { freq }\end{array}$ & $\begin{array}{l}\text { Mut } \\
\text { chr }\end{array}$ & $\begin{array}{c}\text { Total } \\
\text { chr }\end{array}$ & $\begin{array}{c}\text { Mut allele } \\
\text { freq }\end{array}$ \\
\hline & Exon1 (5'UTR) & c. $-91 \mathbf{G}>\mathbf{A}^{b}$ & & 2 & 332 & $\mathbf{0 . 0 0 6 0}$ & $\mathbf{0}$ & 368 & $\mathbf{0 . 0 0 0 0}$ \\
\hline & Exon1 (5'UTR) & c. $-\mathbf{8 1 T}>\mathbf{C}^{\mathrm{b}}$ & & 1 & 362 & 0.0028 & $\mathbf{0}$ & 368 & 0.0000 \\
\hline rs1804687 & Exon1 (5'UTR) & c. $-52 \mathrm{G}>\mathrm{C}$ & & 15 & 352 & 0.0426 & 16 & 332 & 0.0482 \\
\hline rs2001409 & Exon1 (5'UTR) & c. $-24 \mathrm{~A}>\mathrm{T}$ & & 65 & 358 & 0.1816 & 65 & 356 & 0.1826 \\
\hline \multirow{8}{*}{ rs1131400 } & Exon2 & c. $21 \mathrm{C}>\mathrm{A}$ & p.Ala7Ala & 75 & 372 & 0.2016 & 67 & 382 & 0.1754 \\
\hline & Exon2 & c.115_117 delCAC & p.His39del & 2 & 728 & $\mathbf{0 . 0 0 2 7}$ & 2 & $\mathbf{3 8 8}$ & 0.0052 \\
\hline & Exon2 & c.456C $>T^{\mathrm{b}}$ & p.His $52 \mathrm{His}$ & $\overline{1}$ & 686 & 0.0015 & $\overline{\mathbf{0}}$ & 382 & 0.0000 \\
\hline & Exon2 & c.479A $>$ T & p.His160Leu & $\mathbf{1}$ & 702 & 0.0014 & $\mathbf{1}$ & 382 & 0.0026 \\
\hline & Exon2 & c.508_534del27 ${ }^{b}$ & p.Ser170_Gly178del ${ }^{c}$ & $\mathbf{1}$ & 702 & 0.0014 & $\mathbf{0}$ & 382 & 0.0000 \\
\hline & Exon2 & ${\text { c.534_535ins } 27^{b}}^{b}$ & p.Gly178_Ser179ins9 ${ }^{c}$ & $\mathbf{1}$ & 702 & 0.0014 & $\mathbf{0}$ & 382 & $\mathbf{0 . 0 0 0 0}$ \\
\hline & Exon2 & c.592_597 delAGCGGC ${ }^{b}$ & p.Ser198_Gly199del ${ }^{c}$ & 1 & 648 & 0.0015 & $\mathbf{0}$ & 378 & 0.0000 \\
\hline & Exon2 (3'UTR) & c.1040C $>$ T & & 13 & 372 & 0.0349 & 10 & 374 & 0.0267 \\
\hline \multirow[t]{2}{*}{ rs1131431 } & Exon2 (3'UTR) & c. $1248 \mathrm{C}>\mathrm{T}$ & & 55 & 374 & 0.1471 & 61 & 382 & 0.1597 \\
\hline & Exon2 (3'UTR) & $\mathbf{c . 1 2 6 8 A}>G^{b}$ & & $\mathbf{1}$ & 372 & 0.0027 & $\mathbf{0}$ & 382 & 0.0000 \\
\hline rs4177 & Exon2 (3'UTR) & c.1497_1499deITTT & & $5 \overline{5}$ & 350 & 0.1571 & 59 & 378 & 0.1561 \\
\hline
\end{tabular}

asystematic nomenclature for SNPs (www.hgvs.org) based on GenBank NM_006079.3 (CITED2 cDNA) and counting +1 as A of the initiation codon. Novel sequence variations are in bold.

bequence variations not found in the control cohort.

'Patient-exclusive CITED2 protein mutations altering transcriptional properties. Mut, mutant; chr, chromosome; freq, frequency. 
showed significantly reduced costimulation capacity compared to wt, and reached only half-maximal coactivation (Fig. 2A). All other CITED2 mutants coactivated TFAP2C to the same extent as the CITED2-wt. Next, we confirmed with a HIF1A responsive reporter system [Huang et al., 1998] that CITED2-wt is an efficient repressor of HIF1A transcriptional activation independently of hypoxia [Bhattacharya et al., 1999]. Again, the p.Ser170_Gly178del mutant displayed a significant loss of activity, as it was only able to repress HIF1A with about $60 \%$ efficiency compared to wt. Moreover, in the HIF1A reporter system, the mutations p.Ser198_Gly199del and p.Gly178_Ser179ins9 also significantly affected the activity of CITED2, revealing only about $75 \%$ repressive activity compared to wt. In contrast, the p.His39del mutation and the p.His160Leu amino acid substitution, which had also been found in controls, did not alter CITED2 mediated HIF1A repression significantly (Fig. 2B). These results show that deletions or insertions within the serine-glycine-rich junction modulate CITED2 signal transduction and point to a causative impact of CITED2 on the development of congenital heart diseases in human.

\section{Influence of CITED2 Mutations on Subcellular Localization}

To further evaluate whether the functional changes are due to altered subcellular localization of the protein, transient transfections were carried out using $\mathrm{N}$ - and C-terminal GFP fusion constructs of mutant and wt CITED2, followed by fluorescence microscopy. CITED2-wt was detected mainly in the nucleus and to a lesser extent in the cytoplasm of HEK and HepG2 cells. However, none of the CITED2 mutations altered cellular localization or expression of the protein (Fig. 3 and data not shown). Thus, the diminished TFAP2 coactivation and HIF1A

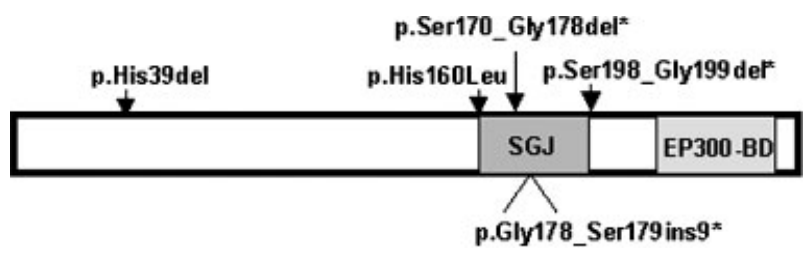

FIGURE 1. Position of mutations in the CITED2 protein observed in CHD patients. The discovered mutations cluster mainly in the serine-glycine rich junction (SGJ; p.Ser161_Gly199), which therefore represents a hotspot for mutations in the protein. The position of the EP300 binding domain (EP300-BD; p.Asp224_Phe255) is indicated. Mutations found only in CHD patients and not in the control cohort are marked with*. repression of the CITED2 mutants are not caused by an incorrect localization of the protein.

\section{Haplotype Analysis of the CITED2 Gene}

Finally, to evaluate the polymorphisms observed in CITED2, we calculated the Hardy-Weinberg equilibrium using multiple tests and a two-sided significance level of $5 \%$. None of the genotyped polymorphisms showed a significant deviation from the HardyWeinberg equilibrium. For the haplotype analysis there were 359 individuals available with successful genotyping for each of the six CITED2 polymorphisms and a minor allele frequency of $>1 \%$. The EM algorithm showed that three out of 32 possible haplotypes exceeded a frequency of $1 \%$, and these accounted for $98.6 \%$ of the chromosomes within our samples, with the main haplotype G-AC-C-C-TTT showing a frequency of $65.4 \%$ (Table 5). An allelic association between the different loci (represented as $\mathrm{D}^{\prime}$ values) is indicated in Figure 4. This analysis suggests the existence of one single haplotype block [Gabriel et al., 2002], and we identified rs1131400 and rs1131431 as haplotype tag (ht) SNPs, which are sufficient for determining the corresponding haplotype. However, none of the common haplotypes showed an association with $\mathrm{CHD}$ when patients and control individuals were compared (data not shown).

\section{DISCUSSION}

Previous reports of mice lacking Cited2 suggested that it plays a direct role in the development of the AV canal and cardiac septa, and that it is required for the normal establishment of the left-right axis. Cited2-/- embryos show a variety of cardiac malformations, including atrial and ventricular septal defects, abnormal heart looping with overriding aorta, and outflow tract abnormalities [Bamforth et al., 2001, 2004; Weninger et al., 2005]. In the present study we analyzed 392 patients with a broad range of CHDs, and discovered seven potential disease-causing mutations in eight patients. These mutations, which were exclusively observed in the patient cohort and not found in 192 control individuals, give rise to cardiac septal defects as well as outflow tract abnormalities associated with malrotation of the great arteries. This reflects the range of defects observed in Cited2-/embryos.

Three of these CITED2 mutations (p.Ser170_Gly178del, p.Gly178_Ser179ins9, and p.Ser198_Gly199del) alter the amino acid sequence and cluster in the serine-glycine rich junction of the protein, which therefore represents a potential hotspot for mutations in CITED2. Our further analysis of these mutations using reporter-gene assays revealed their functional implications

TABLE 4. CITED2 Mutations Identified among 392 Patients with Congenital Heart Disease

\begin{tabular}{|c|c|c|c|}
\hline Nucleotide variation & Amino acid variation & \# Patients & Type of congenital heart defect \\
\hline c. $-91 \mathrm{G}>\mathrm{A}$ & & 2 & $\begin{array}{l}\text { Tetralogy of Fallot } \\
\text { Perimembranous ventricular septal defect and secundum atrial } \\
\text { septal defect }\end{array}$ \\
\hline c. $-81 \mathrm{~T}>\mathrm{C}$ & & 1 & $\begin{array}{l}\text { Situs inversus totalis, transposition of the great arteries and } \\
\text { perimembranous ventricular septal defect }\end{array}$ \\
\hline c. $456 \mathrm{C}>\mathrm{T}$ & p.His $52 \mathrm{His}$ & 1 & $\begin{array}{l}\text { Perimembranous ventricular septal defect and right ventricular } \\
\text { outflow tract obstruction }\end{array}$ \\
\hline c.508_534del27 & p.Ser170_Gly178del & 1 & Perimembranous ventricular septal defect \\
\hline c.534_535ins 27 & p.Gly178_Ser179ins9 & 1 & Secundum atrial septal defect \\
\hline c.592_597delAGCGGC & p.Ser198_Gly199del & 1 & $\begin{array}{l}\text { Sinus venosus atrial septal defect, abnormal pulmonary venous } \\
\text { return to the right atria }\end{array}$ \\
\hline c. $1268 \mathrm{~A}>\mathrm{G}$ & & 1 & Tetralogy of Fallot \\
\hline
\end{tabular}



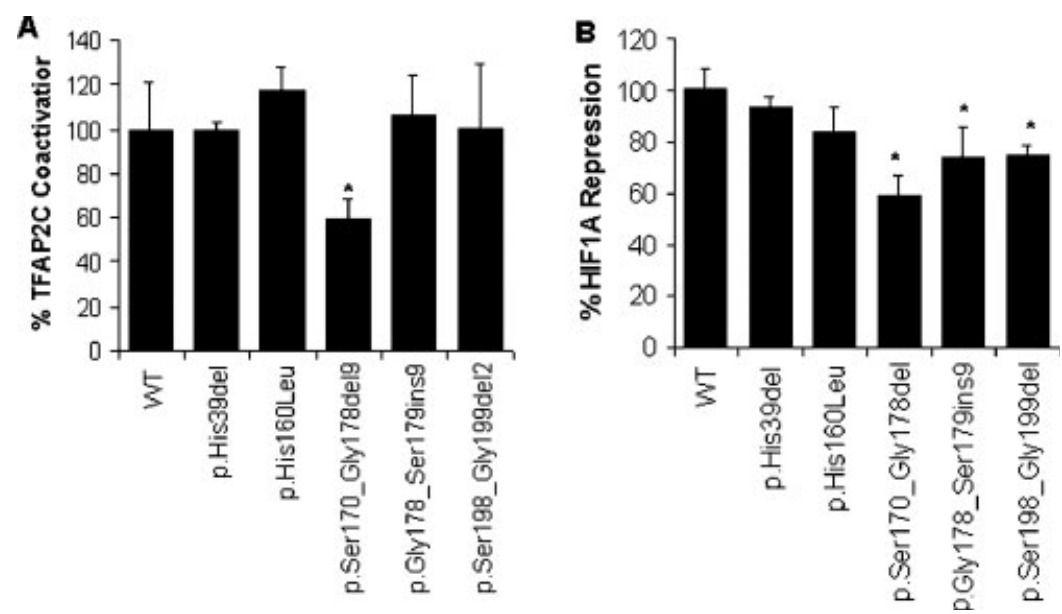

FIGURE 2. Transcriptional modulation of CITED2 variants. Luciferase activity of a TFAP2C-stimulated TFAP2-reporter construct (A) and a Gal4-HIF1A stimulated Gal4-reporter construct (B) cotransfected with CITED2-wt or mutant constructs as indicated. The specific CITED2 construct used is shown below each bar. Luciferase activities were measured and the mean fold-coactivation/ repression as compared to wt is expressed as a percentage. Each bar represents a minimum of three independent experiments performed in at least triplicates ( ${ }^{*}$ significantly different from wt, $\mathrm{P}<0.05$ ).
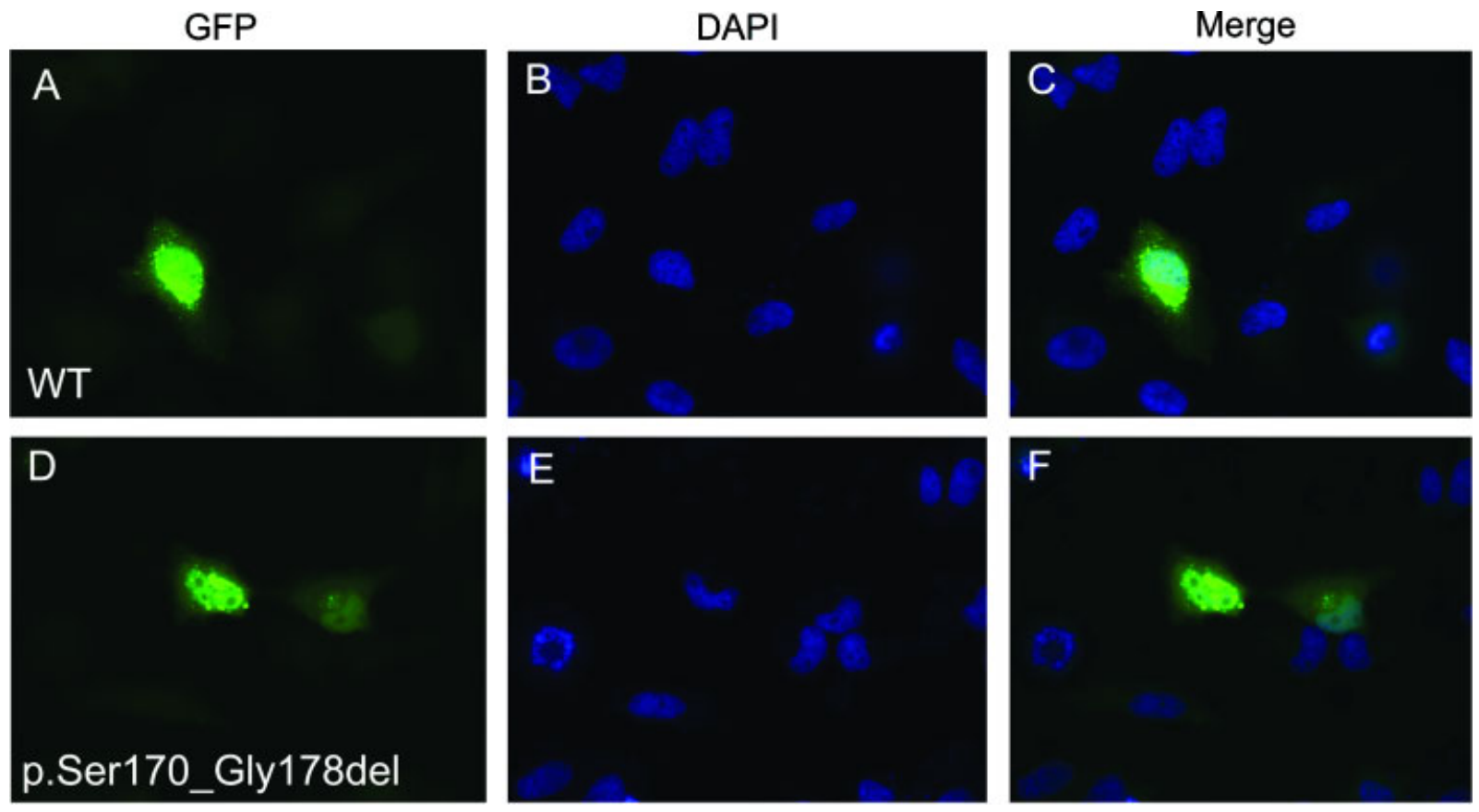

FIGURE 3. Subcellular localization of CITED2. For CITED2-wt and the p.Ser170_Gly178del mutant fluorescence of GFP-fusion proteins ( $\mathbf{A}$ and $\mathbf{D})$ and DAPI staining ( $\mathbf{B}$ and $\mathbf{E})$ are shown individually and merged (C and $\mathbf{F})$.

TABLE 5. CITED2 Haplotypes With Estimated Frequencies $>1 \%$

\begin{tabular}{lcc}
\hline No. & Haplotype $^{\mathrm{a}}$ & Frequency (\%) \\
\hline 1 & G-A-C-C-C-TTT & 65.4 \\
2 & G-T-A-C-C-TTT & 18.3 \\
3 & G-A-C-C-T-deITTT & 14.9 \\
\hline
\end{tabular}

${ }^{\text {a }}$ Haplotypes are designated with the SNPs in the following order: rs1804687-rs2001409-rs1131400-c.1040C > T-rs1131431-rs4177. htSNPs are in bold.

(e.g., all three mutations lead to a significant loss in HIF1A transcriptional repressive capacity of CITED2). Moreover, we observed a significantly diminished TFAP2C coactivation of the p.Ser170_Gly178del mutant. These findings indicate a modifying role for the serine-glycine rich junction in CITED2 function, to which no functionality had been assigned to date. One might speculate that variations in this region cause conformational changes, altering the ability of the EP300 binding domain to interact with CREBBP and EP300 or to recruit other cofactors.

This suggests that the detected CITED2 mutations are potential risk factors for CHD and account for $\sim 2 \%$ (8/392) of our patient cohort of sporadic CHD cases. The broad phenotypical spectrum of heart defects seen in Cited2-/- mice, as well as in our patients, points to other, potentially relevant but currently unknown modifying factors. In the future it will be of interest to evaluate the functionality of the serine-glycine-rich junction of CITED2 and the non-amino acid altering mutations observed in the coding region, the 5'UTR and 3'UTR. To gain insights into the 


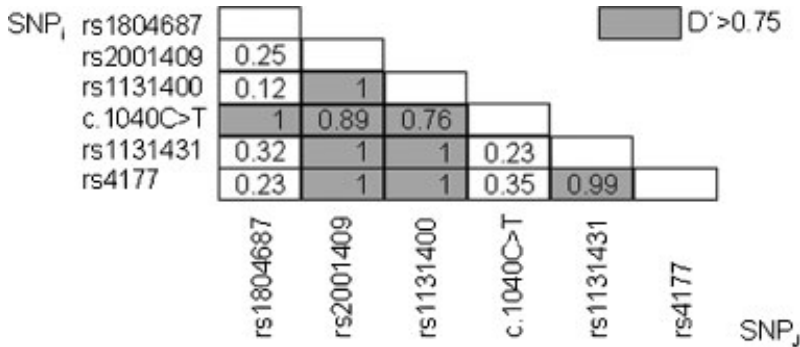

FIGURE 4. Pairwise allelic association of SNPs in CITED2 as measured by $\mathrm{D}^{\prime}$ (numbers). Only SNPs with minor allele frequencies $>1 \%$ are included.

inheritance of the mutations, it would be useful to analyze family triplets, which unfortunately were not available for the present study.

Finally, in a comparison of patients and controls we did not observe any significant differences in allele frequencies of the common variants, in accordance with a previous study [Volcik et al., 2004]. Haplotype analysis showed that only three out of 32 possible haplotypes accounted for at least $98.6 \%$ of the investigated chromosomes, which suggests the existence of only one haplotype block (Table 5; Fig. 4). Therefore, two htSNPs were extracted that are sufficient for haplotype determination.

In summary, we present the first evidence that CITED2 is a disease-causing gene for congenital heart malformations (particularly septal defects and malrotations of the great arteries) in humans.

\section{ACKNOWLEDGMENTS}

We thank Bernd Timmermann for the haplotype analysis, Bettina Moser and Richard Reinhardt for the DHPLC analysis, and Stefan Wiemann for helpful discussions. We are deeply grateful to the patients and families for their cooperation.

\section{REFERENCES}

Bamford RN, Roessler E, Burdine RD, Saplakoglu U, dela Cruz J, Splitt M, Goodship JA, Towbin J, Bowers P, Ferrero GB, Marino B, Schier AF, Shen, Muenke M, Casey B. 2000. Loss-of-function mutations in the EGF-CFC gene CFC1 are associated with human left-right laterality defects. Nat Genet 26:365-369.

Bamforth SD, Braganca J, Eloranta JJ, Murdoch JN, Marques FI, Kranc KR, Farza H, Henderson DJ, Hurst HC, Bhattacharya S. 2001. Cardiac malformations, adrenal agenesis, neural crest defects and exencephaly in mice lacking Cited2, a new Tfap2 co-activator. Nat Genet 29:469-474.

Bamforth SD, Braganca J, Farthing CR, Schneider JE, Broadbent C, Michell AC, Clarke K, Neubauer S, Norris D, Brown NA, Anderson RH, Bhattacharya S. 2004. Cited2 controls left-right patterning and heart development through a Nodal-Pitx2c pathway. Nat Genet 36:1189-1196.

Barrett JC, Fry B, Maller J, Daly MJ. 2005. Haploview: analysis and visualization of $\mathrm{LD}$ and haplotype maps. Bioinformatics 21: 263-265.

Basson CT, Bachinsky DR, Lin RC, Levi T, Elkins JA, Soults J, Grayzel D, Kroumpouzou E, Traill TA, Leblanc-Straceski J, Renaul B, Kucherlapati R, Seidman JG, Seidman CE. 1997. Mutations in human TBX5 [corrected] cause limb and cardiac malformation in Holt-Oram syndrome. Nat Genet 15:30-35.
Bhattacharya S, Michels CL, Leung MK, Arany ZP, Kung AL, Livingston DM. 1999. Functional role of p35srj, a novel p300/ CBP binding protein, during transactivation by HIF-1. Genes Dev 13:64-75.

Bosher JM, Totty NF, Hsuan JJ, Williams T, Hurst HC. 1996. A family of AP-2 proteins regulates c-erbB-2 expression in mammary carcinoma. Oncogene 13:1701-1707.

Braganca J, Eloranta JJ, Bamforth SD, Ibbitt JC, Hurst HC, Bhattacharya S. 2003. Physical and functional interactions among AP-2 transcription factors, p300/CREB-binding protein, and CITED2. J Biol Chem 278:16021-16029.

Ching YH, Ghosh TK, Cross SJ, Packham EA, Honeyman L, Loughna S, Robinson TE, Dearlove AM, Ribas G, Bonser AJ, Thomas NR, Scotter AJ, Caves LS, Tyrrell GP, Newbury-Ecob RA, Munnich A, Bonnet D, Brook JD. 2005. Mutation in myosin heavy chain 6 causes atrial septal defect. Nat Genet 37: 423-428.

Eng C, Brody LC, Wagner TM, Devilee P, Vijg J, Szabo C, Tavtigian SV, Nathanson KL, Ostrander E, Frank TS. 2001. Interpreting epidemiological research: blinded comparison of methods used to estimate the prevalence of inherited mutations in BRCA1. J Med Genet 38:824-833.

Freedman SJ, Sun ZY, Kung AL, France DS, Wagner G, Eck MJ. 2003. Structural basis for negative regulation of hypoxiainducible factor-1alpha by CITED2. Nat Struct Biol 10: 504-512.

Gabriel SB, Schaffner SF, Nguyen H, Moore JM, Roy J, Blumenstiel B, Higgins J, DeFelice M, Lochner A, Faggart M, Liu-Cordero SN, Rotimi C, Adeyemo A, Cooper R, Ward R, Lander ES, Daly MJ, Altshuler D. 2002. The structure of haplotype blocks in the human genome. Science 296:2225-2229.

Garg V, Kathiriya IS, Barnes R, Schluterman MK, King IN, Butler CA, Rothrock CR, Eapen RS, Hirayama-Yamada K, Joo K, Mastsuoka R, Cohen JC, Srivastava D. 2003. GATA4 mutations cause human congenital heart defects and reveal an interaction with TBX5. Nature 424:443-447.

Huang LE, Gu J, Schau M, Bunn HF. 1998. Regulation of hypoxiainducible factor 1alpha is mediated by an O2-dependent degradation domain via the ubiquitin-proteasome pathway. Proc Natl Acad Sci USA 95:7987-7992.

Jones AC, Austin J, Hansen N, Hoogendoorn B, Oefner PJ, Cheadle JP, O'Donovan MC. 1999. Optimal temperature selection for mutation detection by denaturing HPLC and comparison to single-stranded conformation polymorphism and heteroduplex analysis. Clin Chem 45 (8 Pt 1):1133-1140.

Kaynak B, von Heydebreck A, Mebus S, Seelow D, Hennig S, Vogel J, Sperling HP, Pregla R, Alexi-Meskishvili V, Hetzer R, Lange PE, Vingron M, Lehrach H, Sperling S. 2003. Genomewide array analysis of normal and malformed human hearts. Circulation 107:2467-2474.

Leung MK, Jones T, Michels CL, Livingston DM, Bhattacharya S. 1999. Molecular cloning and chromosomal localization of the human CITED2 gene encoding p35srj/Mrg1. Genomics 61: 307-313.

Li QY, Newbury-Ecob RA, Terrett JA, Wilson DI, Curtis AR, Yi CH, Gebuhr T, Bullen PJ, Robson SC, Strachan T, Bonnet D, Lyonnet S, Young ID, Raeburn JA, Buckler AJ, Law DJ, Brook JD. 1997. Holt-Oram syndrome is caused by mutations in TBX5, a member of the Brachyury ( $\mathrm{T}$ ) gene family. Nat Genet 15:21-29.

Myakishev MV, Khripin Y, Hu S, Hamer DH. 2001. High-throughput SNP genotyping by allele-specific PCR with universal energy-transfer-labeled primers. Genome Res 11:163-169. 
Olson EN. 2004. A decade of discoveries in cardiac biology. Nat Med 10:467-474.

Petrij F, Giles RH, Dauwerse HG, Saris JJ, Hennekam RC, Masuno M, Tommerup N, van Ommen GJ, Goodman RH, Peters DJ, Breuning MH. 1995. Rubinstein-Taybi syndrome caused by mutations in the transcriptional co-activator CBP. Nature 376:348-351.

Pizzuti A, Sarkozy A, Newton AL, Conti E, Flex E, Digilio MC, Amati F, Gianni D, Tandoi C, Marino B, Crossley M, Dallapiccola B. 2003. Mutations of ZFPM2/FOG2 gene in sporadic cases of tetralogy of Fallot. Hum Mutat 22:372-377.

Reamon-Buettner SM, Borlak J. 2004. TBX5 mutations in nonHolt-Oram syndrome (HOS) malformed hearts. Hum Mutat 24:104.

Rickert AM, Borodina TA, Kuhn EJ, Lehrach H, Sperling S. 2004. Refinement of single-nucleotide polymorphism genotyping methods on human genomic DNA: amplifluor allele-specific polymerase chain reaction versus ligation detection reactionTaqMan. Anal Biochem 330:288-297.

Roelfsema JH, White SJ, Ariyurek Y, Bartholdi D, Niedrist D, Papadia F, Bacino CA, den Dunnen JT, van Ommen GJ, Breuning MH, Hennekam RC, Peters DJ. 2005. Genetic heterogeneity in Rubinstein-Taybi syndrome: mutations in both the CBP and EP300 genes cause disease. Am J Hum Genet 76: 572-580.

Schott JJ, Benson DW, Basson CT, Pease W, Silberbach GM, Moak JP, Maron BJ, Seidman CE, Seidman JG. 1998. Congenital heart disease caused by mutations in the transcription factor NKX2-5. Science 281:108-111.

Seelow D, Galli R, Mebus S, Sperling HP, Lehrach H, Sperling S. 2004. d-matrix-database exploration, visualization and analysis. BMC Bioinformatics 5:168.

Solloway MJ, Harvey RP. 2003. Molecular pathways in myocardial development: a stem cell perspective. Cardiovasc Res 58: 264-277.

Srivastava D. 2001. Genetic assembly of the heart: implications for congenital heart disease. Annu Rev Physiol 63:451-469.

Volcik KA, Zhu H, Finnell RH, Shaw GM, Canfield M, Lammer EJ. 2004. Evaluation of the Cited2 gene and risk for spina bifida and congenital heart defects. Am J Med Genet A 126:324-325.

Ware SM, Peng J, Zhu L, Fernbach S, Colicos S, Casey B, Towbin J, Belmont JW. 2004. Identification and functional analysis of ZIC3 mutations in heterotaxy and related congenital heart defects. Am J Hum Genet 74:93-105.

Weninger WJ, Floro KL, Bennett MB, Withington SL, Preis JI, Barbera JP, Mohun TJ, Dunwoodie SL. 2005. Cited2 is required both for heart morphogenesis and establishment of the left-right axis in mouse development. Development 132:1337-1348.

Yin Z, Haynie J, Yang X, Han B, Kiatchoosakun S, Restivo J, Yuan S, Prabhakar NR, Herrup K, Conlon RA, Hoit BD, Watanabe M, Yang YC. 2002. The essential role of Cited2, a negative regulator for HIF-1alpha, in heart development and neurulation. Proc Natl Acad Sci USA 99:10488-10493. 